\title{
Ultrastructure of rat umbilical cord stroma-derived mesenchymal stem cells
}

\author{
Ahmet CEYLAN $^{1}{ }^{1}$, Özge ÖZGENÇ ${ }^{1}$, Korhan ALTUNBAŞ $^{2}$, Petek KORKUSUZ $^{3}$, Asuman ÖZEN $^{1}$ \\ ${ }^{1}$ Department of Histology and Embryology, Faculty of Veterinary Medicine, Ankara University, Ankara, Turkey \\ ${ }^{2}$ Department of Histology and Embryology, Faculty of Veterinary Medicine, Afyon Kocatepe University, Afyonkarahisar, Turkey \\ ${ }^{3}$ Department of Histology and Embryology, Faculty of Medicine, Hacettepe University, Ankara, Turkey
}

Received: $16.01 .2017 \quad \bullet \quad$ Accepted/Published Online: 06.07.2017 • Final Version: 21.08.2017

\begin{abstract}
Being multipotent progenitor cells, mesenchymal stem cells continue to attract attention as a promising tool for cell-based therapy and tissue engineering. However, research on the ultrastructure of these cells is rather scarce. This study was aimed at the investigation of the transmission electron microscopic ultrastructure and morphology of mesenchymal stem cells isolated from the stroma of rat umbilical cord using the explant culture method. At the end of the third passage, some of the cells isolated from the stroma of the umbilical cord were harvested for electron microscopic examination. The remaining cells were induced for osteogenic, chondrogenic, and adipogenic differentiation. On the basis of the results obtained, it was concluded that mesenchymal stem cells derived from the stroma of the umbilical cord display morphological features similar to those of other types of mesenchymal stem cells and can be used as an alternative cell source in cell-based therapy owing to the advantages they offer.
\end{abstract}

Key words: Umbilical cord, mesenchymal stem cells, ultrastructure, rat

\section{Introduction}

Mesenchymal stem cells (MSCs) are self-renewing and multipotent cells, which have the potential to differentiate into various tissue cells, including osteoblasts $(1,2)$, adipocytes, chondrocytes (3), neurons, glia cells (4), and cardiomyocytes (5), under favorable conditions. Owing to this potential, MSCs are being increasingly investigated for their use in cell-based regenerative medicine and tissue engineering (6).

In recent years, MSCs have been reported to be isolated from various tissues, including adipose tissue, cartilaginous tissue, muscles, tendons, the periodontal ligament, synovial membranes, trabecular bone and bone marrow, umbilical cords, placentas, the nervous system, skin, the periosteum, fetal liver, and dental pulp (7-9).

The umbilical cord (UC), which is of varying length in different species, is a transparent flexible tissue externally surrounded by the amniotic membrane and composed of three blood vessels, including two arteries and one vein, which are encapsulated by a mucous connective tissue referred to as Wharton's jelly (10). Although the umbilical cord appears to be homogeneous at macroscopic level, it has been shown to comprise three compartments on the basis of the proliferation and differentiation characteristics determined for expanded stromal cells. These

*Correspondence: ceylan@ankara.edu.tr compartments are the subamniotic stroma, intervascular stroma, and perivascular stroma (11).

UC-derived MSCs can be isolated from Wharton's jelly, the perivascular stroma, and the subamniotic membrane $(10,12)$. Human UC-derived MSCs offer several advantages, including their isolation being easier, noninvasive, and less contentious when compared to that of MSCs isolated from the bone marrow and adipose tissue, as well as their contamination risk being lower and their differentiation and immunomodulatory capacity being higher (13).

Although several studies have been carried out to demonstrate various features of these cells, including their phenotypic characteristics and plasticity, the number of studies available on the ultrastructure of MSCs is rather limited. This study was aimed at determining the plasticity of UC-derived MSCs isolated from the rat and also at demonstrating, for the first time, the ultrastructural characteristics of these cells in detail.

\section{Materials and methods}

2.1. Isolation and expansion of umbilical cord-derived mesenchymal stem cells

UC samples were collected from the fetuses of pregnant Wistar albino rats under general anesthesia. Immediately 
after the removal of the umbilical arteries and vein, the remaining tissue parts were transferred under aseptic conditions to a sterile petri dish containing Dulbecco's modified Eagle's medium (DMEM) (Lonza, Belgium) and antibiotics $(100 \mu \mathrm{g} / \mathrm{mL}$ penicillin, $10 \mu \mathrm{g} / \mathrm{mL}$ streptomycin, and $250 \mu \mathrm{g} / \mathrm{mL}$ amphotericin B; Invitrogen Life Sciences, USA). After being mechanically cut into smaller pieces, the tissue explants were transferred to a T25 culture flask and maintained in an incubator for $15 \mathrm{~min}$ in an atmosphere of $5 \% \mathrm{CO}_{2}$ at $37^{\circ} \mathrm{C}$. This was followed by incubation in a medium containing 20\% fetal calf serum (Lonza); $2 \%$ L-glutamine (Lonza); $1 \%$ penicillin, streptomycin, and amphomycin (Biological Industries, Israel); and $77 \%$ DMEM (Lonza). The medium was renewed every 3 days and nonadherent cells were removed. At approximately $70 \%$ confluency, the adherent MSCs were passaged with $0.25 \%$ trypsin in PBS, counted, and plated again. Plated cells were monitored during the first expansion period for several days before the first passage. Cell plating density was calculated at $3 \times 10^{4}$ cells per square centimeter in the first passage. Total viable cells per sample were counted using trypan blue dye. The cells were grown until the third passage. The trial was conducted with the permission of the Board of Ethics in Animal Experiments of Ankara University (2016-4-35).

\subsection{Differentiation protocol}

In order to characterize the harvested cells at the third passage, the cells were stimulated into osteogenic, adipogenic, chondrogenic, and neurosphere differentiation in a monolayer culture. For osteogenic, adipogenic, chondrogenic, and neurosphere differentiation, the cells were seeded into a six-well plate at a density of $5.0 \times 10^{4}$ cells $/ \mathrm{cm}^{2}$.

For osteogenic differentiation, an osteocyte differentiation basal medium consisting of low-glucose DMEM, $0.05 \mathrm{mM}$ ascorbate-2-phosphate, $100 \mathrm{nM}$ dexamethasone, and $10 \mathrm{mM}$ sodium $\beta$-glycerophosphate (GIBCO, USA) was used. The cells were expanded in a monolayer culture for a period of 3 weeks and the medium was renewed every 3 days.

For adipogenic differentiation, the cells were induced for 18 days. The cells were first cultured in an adipogenic induction medium containing standard medium highglucose DMEM (10\% fetal bovine serum (FBS)), 0.5 $\mathrm{mM}$ 3-isobutyl-1-methylxanthine, $1 \mu \mathrm{M}$ dexamethasone, $10 \mu \mathrm{g} / \mathrm{mL}$ insulin, and $0.5 \mathrm{mM}$ indomethacin (GIBCO) for $72 \mathrm{~h}$. Later, the cells were exposed to an adipogenic maintenance medium for 2 days. This treatment cycle was repeated twice.

For chondrogenic differentiation, the cells were induced for 18 days in standard medium high-glucose DMEM containing $6.25 \mu \mathrm{g} / \mathrm{mL}$ insulin-transferrinselenous acid, $0.1 \mathrm{mM}$ ascorbate-2-phosphate, $10^{-7} \mathrm{M}$ dexamethasone, $1.25 \mathrm{mg} / \mathrm{mL}$ bovine serum albumin, 5000 $\mathrm{IU} / \mathrm{mL}$ penicillin, $5000 \mu \mathrm{g} / \mathrm{mL}$ streptomycin, $50 \mu \mathrm{g} / \mathrm{mL}$ ascorbate 2-phosphate, $100 \mathrm{nM}$ dexamethasone, and 10 $\mathrm{ng} / \mathrm{mL}$ human transforming growth factor.

For neurosphere differentiation, the culture medium in the flask was aspirated and the cells were washed with Hanks' balanced salt solution. After the cells were incubated in a trypsin-EDTA solution for $5 \mathrm{~min}$, the enzymatic reaction was terminated by adding FBS and the mixture was transferred into $15-\mathrm{mL}$ tubes to be centrifuged at $250 \times g$ for $10 \mathrm{~min}$. After the supernatant was discarded, the cells were suspended in a serum-free culture medium (DMEM/HAM F12 supplemented with insulin, transferrin, and selenium (ITS-X 1\%); EGF (50 $\mathrm{ng} / \mathrm{mL})$; FGF2 (50 $\mathrm{ng} / \mathrm{mL})$; and $1 \%$ pen/strep) and seeded into $25-\mathrm{cm}^{2}$ flasks coated with poly-D-lysine.

\subsection{Histochemical staining}

The differentiation of cells into the adipogenic, osteogenic, and chondrogenic lineages was demonstrated using different histological staining techniques. The von Kossa staining method (Merck, Germany, Lot HC392067) showed the deposition of minerals in the osteogenic cultures. Adipogenic differentiation was evaluated using Oil Red O stain (Sigma Aldrich, USA, Lot SLBC9102V) on the basis of lipid droplet accumulation in the cell cytoplasm. Alcian Blue ( $\mathrm{pH}$ 2.5) (Millipore, USA, Lot 2496226) staining was used to show chondrogenic differentiation on the basis of the production of a ground substance matrix.

\subsection{Ultrastructure analysis by transmission electron microscopy (TEM)}

In order to evaluate the ultrastructure of the UCs, the cells at passage three were fixed immediately upon harvesting in $2 \%$ glutaraldehyde in $0.1 \mathrm{M}$ cacodylate buffer ( $\mathrm{pH} 7.4$ ) at 4 ${ }^{\circ} \mathrm{C}$ for $2 \mathrm{~h}$. The cells were rinsed in $1 \mathrm{M}$ sodium cacodylate (195 mOsm, pH 7.4) four times for $1 \mathrm{~h}$ and postfixed in $2 \%$ osmium tetroxide in $0.5 \mathrm{M}$ sodium cacodylate buffer for $2 \mathrm{~h}$. Subsequently, the cells were dehydrated in graded ethanol, passed through propylene oxide, and embedded in Epon-araldite (EMS, Germany) using an automated tissue processor. Thin sections were stained with uranyl acetate and lead citrate with an automated staining machine (Leica, Germany). The sections were examined under a transmission electron microscope (JEOL, Japan, JEM1400) and photographed with a Gatan Orius SC 200 W CCD camera. Electron micrographs were taken at original magnifications of $4000 \times$ to $21,000 \times$ and enlarged photographically as desired.

\section{Results}

3.1. Expansion period and differentiation of UCs into mesenchymal lineages and neuronal lineage

Fibroblast-like spindle-shaped cells were observed at 
36-48 $\mathrm{h}$ after incubation, starting from the peripheral area of the UCs expanded by the explant culture method. Homogeneous and symmetrical colonies, which had adhered to the plastic surface, were observed on days 6-7. The cells forming these colonies were observed to be morphologically similar to the mesenchymal stem cells of the bone marrow. The colonies reached a confluency of $80 \%-90 \%$ at the end of the first week. A total of $2.7 \pm 0.5$ $\times 10^{6}$ viable cells per sample were obtained after the first expansion period.

The colonies of the cells induced for osteogenic differentiation displayed dents comprising amorphous aggregates from day 9. The number and distribution of these dents reached a maximum at the end of the second week. The von Kossa staining method confirmed these dents to be calcium deposits.

The cells of the colonies induced for adipogenic differentiation started to display an ovoid morphology from days 11-13, and lipid droplets were observed in the periphery. At the end of the third week, the cells were stained with Oil Red $\mathrm{O}$ to demonstrate their adipogenic differentiation. In the colonies induced for chondrogenic differentiation, the presence of nodules secreting cartilagespecific proteoglycans, which were observed from day 19 , was demonstrated by Alcian Blue staining (Figure 1).

Neurosphere formation was observed from $24 \mathrm{~h}$ after the induction of the colonies into neurosphere differentiation. From $72 \mathrm{~h}$, the neurospheres were observed to disappear in the culture medium. The optimum timing for the harvesting of the neurospheres was determined to be the 40th hour (Figure 2).

\subsection{Ultrastructural characteristics of the UCs}

TEM revealed that the UCs had a rather large, eccentrically located, polymorphic, lobulated euchromatic nucleus and a distinct nucleolus. These morphological features were typically indicative of high transcriptional activity, or in other words ongoing protein synthesis in the nucleus. In general, the cells displayed a spheroid polygonal
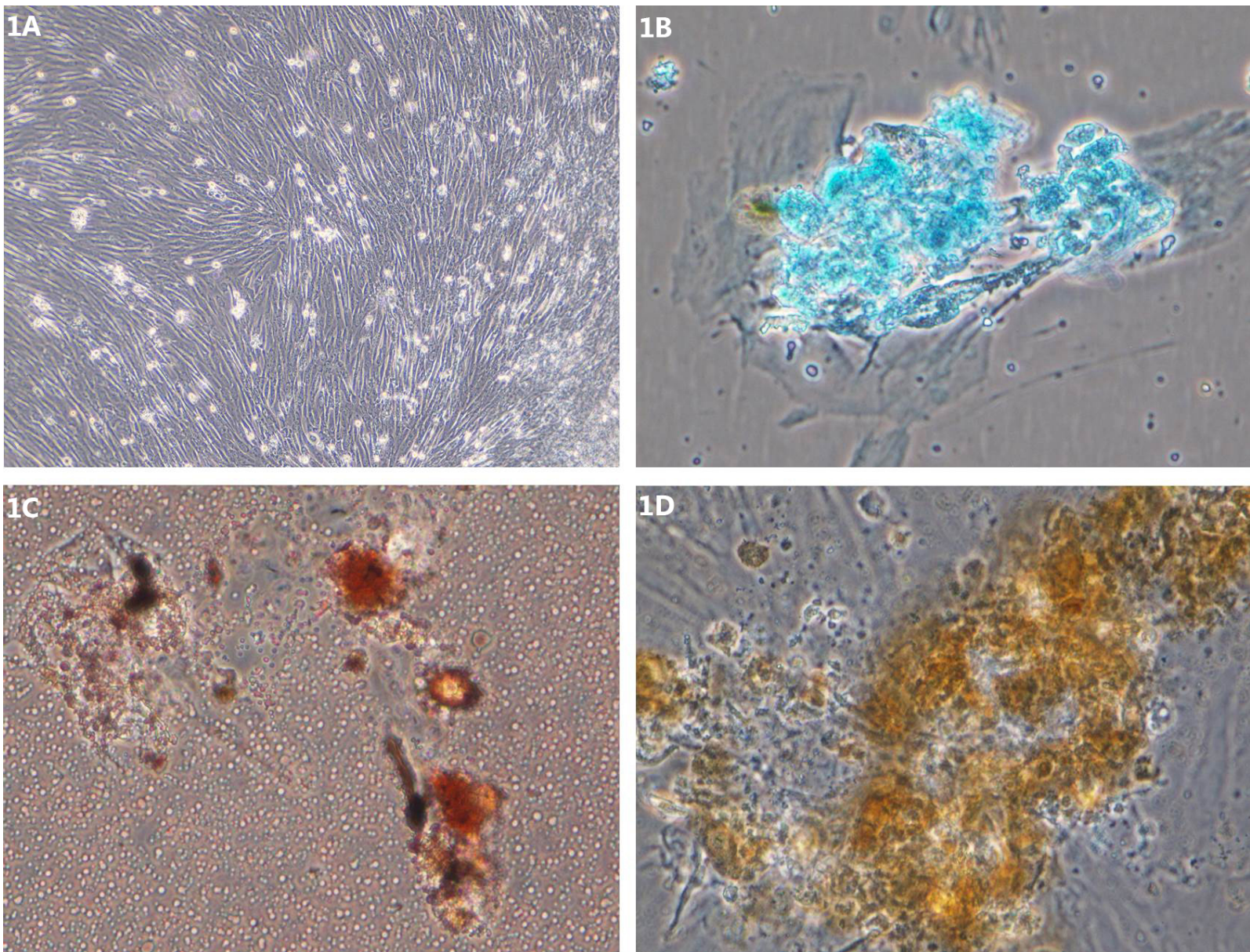

Figure 1. A) The cultured MSCs showing colony forming unit fibroblast (CFU-U) morphology B) Chondrogenic differentiation with Alcian Blue showing glycosaminoglycans. C) Adipogenic differentiation with Oil Red O stain showing fat vacuoles throughout the culture. D) Osteogenic differentiation with von Kossa showing calcium deposition in cultures. 


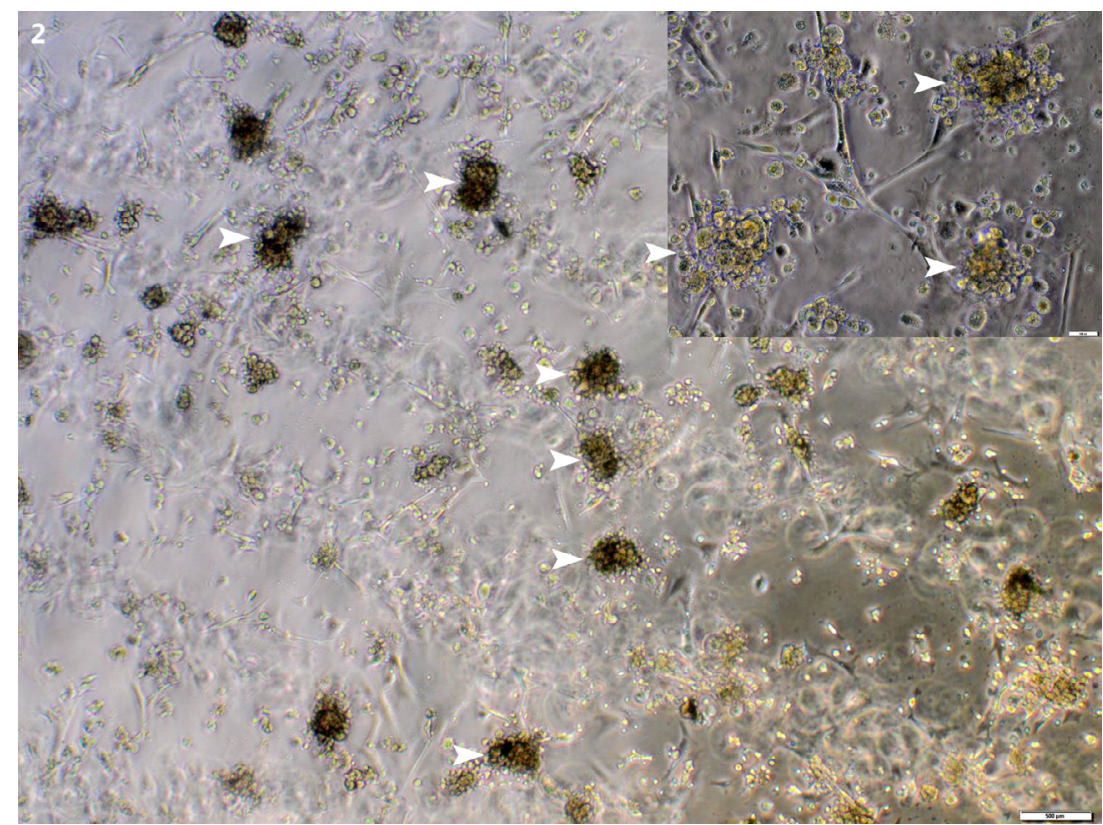

Figure 2. MSC differentiation into neurosphere (arrowheads).

morphology. The cytoplasm was rich in organelles and contained abundant mitochondria, Golgi complexes, free ribosomes, and polysomes. Particularly in the periphery of the nucleus, the presence of a highly organized and enlarged granular endoplasmic reticulum was noteworthy. While it was observed that the organelles were concentrated to a greater extent in the cytoplasmic area surrounding the nucleus, the rest of the cytoplasm showed the opposite situation. Almost all cells were observed to have synthesized vesicles that displayed a peripheral distribution. The cell membrane had multiple pseudopodlike protrusions, which enabled the adherence of the cells to the surface of the flask. These structures, which contained multiple vesicles, were organized particularly in the areas where the cells came into contact with each other. In these contact areas, focal points of adhesion were observed on the neighboring pseudopod-like protrusions. Furthermore, neither glycogen nor lipid vacuoles or contractile filaments were observed in the periphery of the cells (Figure 3).

\section{Discussion}

UC-derived MSCs have been investigated in depth by several researchers in view of the multiple advantages they offer, including their isolation being easier and ethically and legally less contentious, their bacterial and viral contamination risk being low, their lacking MHC II expression, and their capacity of differentiating into cells originating from all three of the embryonic germ layers $(6,10,14-16)$. Furthermore, it has been reported that mesenchymal stem cells derived from the UC stroma provide a major advantage in cell-based therapy in cases where there is a need for the expansion of a high number of cells $(6,17)$. On the other hand, research on the ultrastructural morphology of these cells is rather scarce. This scarcity is ascribed to the expansion of cells by cell culture for electron microscopy being laborious and requiring experience. A study carried out in 2015 showed that exosomes, which are small membrane-bound vesicles synthesized by MSCs, are involved in wound healing as they activate the signalization pathways (18). This involvement requires the demonstration of the detailed ultrastructure of these cells. In this study, the ultrastructure of mesenchymal stem cells, which were isolated from the subamniotic stroma of rat UC by the explant culture method, was investigated for the first time by TEM.

It has been reported that the enzymatic digestion method, which is frequently used for the isolation of UC-derived MSCs, damages the cellular junctions, increases cellular heterogeneity, and alters the immune phenotype (19). On the other hand, the explant culture method is known to maintain cell uniformity and to facilitate the expansion of a high number of cells $(20,21)$. A widely accepted protocol has not yet been developed for the employment of this method. In this study, the explant culture method was employed on the basis of the experience of the researchers such that the cellular junctions were protected to ensure the generation of more reliable ultrastructural findings. For this purpose, the blood vessels, perivascular stroma, and intervascular stroma were dissected and eliminated to the largest extent possible. In this study, only a certain part of the UC was 

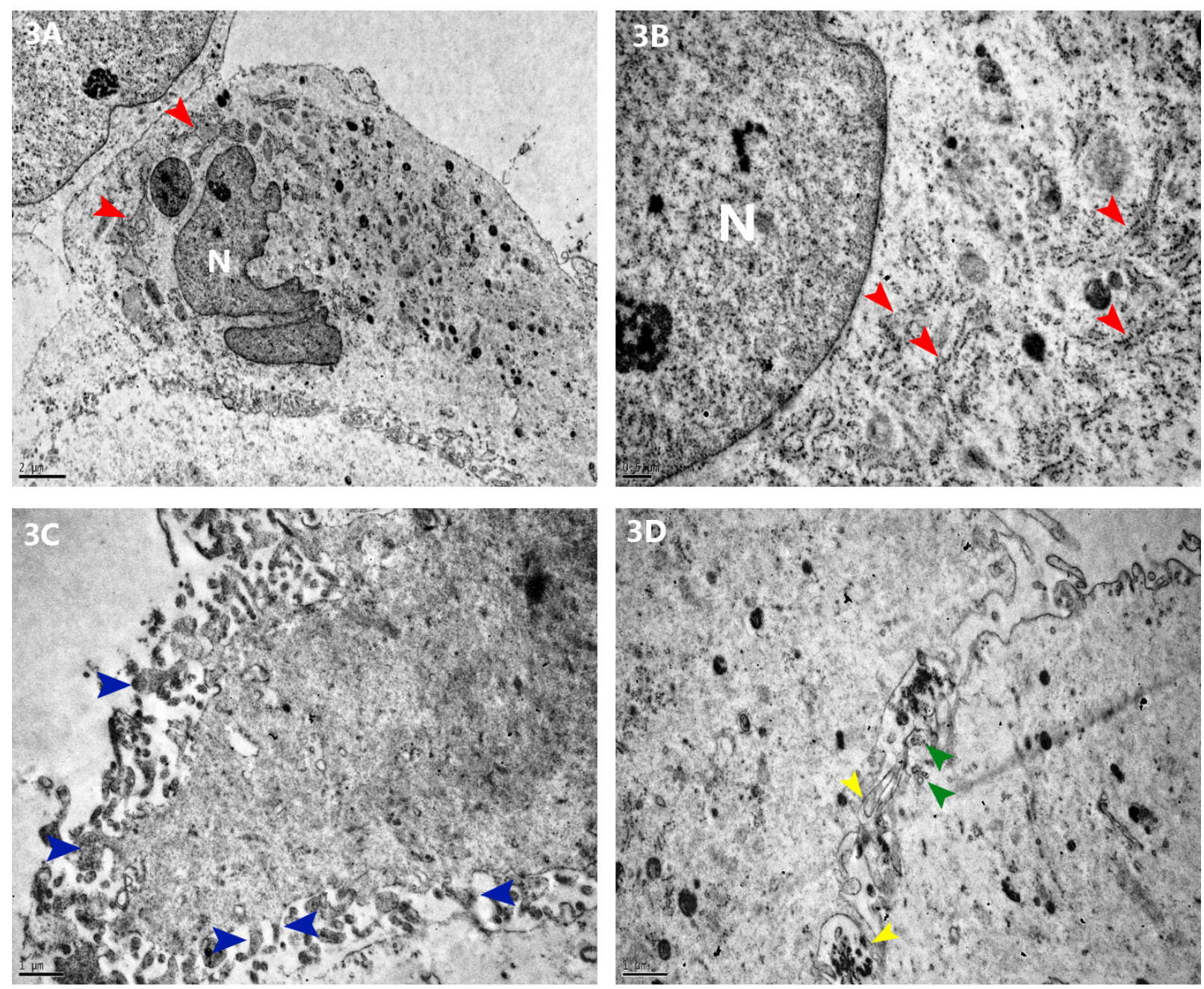

Figure 3. A) Eccentrically located polymorphic, lobulated nucleus (N) and granular endoplasmic reticulum (red arrowheads). B) Euchromatic nucleus (N) and enlarged granular endoplasmic reticulum (red arrowheads). C) Pseudopod-like protrusions (blue arrowheads). D) Focal points of adhesion between cells (yellow arrowheads), multiple vesicles (green arrowheads).

able to be assessed, and currently there is no definitive information available on whether the different regions of the UC differ in their differentiation capacity. However, in a study on the comparative evaluation of MSCs isolated from different regions of the UC, it was demonstrated that the osteogenic differentiation capacity of MSCs isolated from Wharton's jelly was lower (22). Furthermore, it has been reported that, owing to the possibility of it containing endothelial cells originating from blood vessels, Wharton's jelly increases the heterogeneity of culture medium (23).

TEM is a method that enables the examination of cell morphology at an ultrastructural level and yields detailed and valuable findings that are considered to be the gold standard (24). To date, the MSCs that have been most frequently investigated for their fine structure are bone marrow-derived MSCs. The most characteristic features of these cells are their euchromatic nucleus and widely distributed and enlarged endoplasmic reticulum in the cytoplasm $(17,25)$. A similar morphology was observed in rat UC-derived MSCs in the present study, which was considered to be a cellular adaptation to ensure the supply of proteins required for the growth and differentiation of these cells. In their study aimed at the investigation of MSCs isolated from the stroma of the human UC by TEM, Qiao et al. (26) reported the observation of two types of cells displaying different morphological features on the basis of their being in the active or passive metabolic period. The cells in the active period contained one nucleus or two nuclei in a single cell and displayed a cytoplasmic structure, rich in organelles, while the cells in the passive period contained a single round or oval-shaped nucleus and presented a smaller number of organelles. These results may have arisen from the researchers having isolated the MSCs using different methods and from the different 
regions of the UC. The observation of cells in different metabolic periods at the ultrastructural level could be a result of an increase in cell heterogeneity, depending on the method used. In light of this, it could be suggested that when isolating MSCs from the UC, the selection of the isolation site bears significance for the purpose sought.

In the present study, in which mesenchymal stem cells were isolated for the first time from the stroma of the rat UC by the explant cell culture method, the

\section{References}

1. Hou T, Xu J, Wu X, Xie Z, Luo F, Zhang Z, Zeng L. Umbilical cord Wharton's jelly: a new potential cell source of mesenchymal stromal cells for bone tissue engineering. Tissue Eng Pt A 2009; 15: 2325-2334.

2. Schneider RK, Puellen A, Kramann R, Raupach K, Bornemann J, Knuechel R, Pérez-Bouza A, Neuss S. The osteogenic differentiation of adult bone marrow and perinatal umbilical mesenchymal stem cells and matrix remodelling in threedimensional collagen scaffolds. Biomaterials 2010; 31: 467-480.

3. Somoza RA, Welter, JF, Correa D, Caplan AI. Chondrogenic differentiation of mesenchymal stem cells: challenges and unfulfilled expectations. Tissue Eng Pt B-Rev 2014; 20: 596608.

4. Mitchell KE, Weiss ML, Mitchell BM, Martin P, Davis D, Morales L, Helwig B, Beerenstrauch M, Abou-Easa K, Hildreth T et al. Matrix cells from Wharton's jelly form neurons and glia. Stem Cells 2003; 21: 50-60.

5. Pereira WC, Khushnooma I, Madkaikar M, Ghosh K. Reproducible methodology for the isolation of mesenchymal stem cells from human umbilical cord and its potential for cardiomyocyte generation. J Tissue Eng Regen Med 2008; 2: 394-399.

6. Fan CG, Zhang QJ, Zhou JR. Therapeutic potentials of mesenchymal stem cells derived from human umbilical cord. Stem Cell Rev 2011; 7: 195-207.

7. Klingemann H, Matzilevich D, Marchand J. Mesenchymal stem cells-sources and clinical applications. Transfus Med Hemother 2008; 35: 272-277.

8. Gruber HE, Deepe R, Hoelscher GL, Ingram JA, Norton HJ, Scannell B, Loeffler BJ, Zinchenko N, Hanley EN, Tapp H. Human adipose-derived mesenchymal stem cells: direction to a phenotype sharing similarities with the disc, gene expression profiling, and coculture with human annulus cells. Tissue Eng Pt A 2010; 16: 2843-2860.

9. Özen A, Gül Sancak İ, Ceylan A, Özgenç Ö. Isolation of adipose tissue-derived stem cells. Turk J Vet Anim Sci 2016; 40: 137-141.

10. Nagamura-Inoue $T$, Haiping $H$. Umbilical cord-derived mesenchymal stem cells: their advantages and potential clinical utility. World J Stem Cells 2014; 6: 195-202. detailed ultrastructural morphology of these cells was demonstrated. The results obtained in the present study showed that MSCs could be easily isolated from the UC and further expanded in culture media. It was concluded that the use of these cells, which have a high potential of differentiating into all of the three embryonic germ layers and display high growth potential, could be advantageous in cell-based therapy.

11. Can A. Kök Hücre Biyolojisi, Türleri ve Tedavide Kullanımı. 1st ed. Ankara, Turkey: Akademisyen Tip Kitabevi; 2014 (in Turkish)

12. Wang HS, Hung SC, Peng ST, Huang CC, Wei HM, Guo YJ, Fu YS, Lai MC, Chen CC. Mesenchymal stem cells in the Wharton's jelly of the human umbilical cord. Stem Cells 2004; 22: 1330-1337.

13. Latifpour M, Shakiba Y, Amidi F, Mazaheri Z, Sobhani A. Differentiation of human umbilical cord matrix-derived mesenchymal stem cells into germ-like cells. Avicenna J Med Biotechnol 2014; 6: 218.

14. Deans RJ, Moseley AB. Mesenchymal stem cells: biology and potential clinical use. Exp Hematol 2000; 28: 875-884.

15. Romanov YA, Svintsitskaya VA, Smirnov VN. Searching for alternative sources of postnatal human mesenchymal stem cells: candidate MSC-like cells from umbilical cord. Stem Cells 2003; 21: 105-110.

16. Lim IJ, Phan TT. Epithelial and mesenchymal stem cells from the umbilical cord lining membrane. Cell Transplant 2014; 23 : 497-503.

17. Wang L, Tran I, Seshareddy K, Weiss ML, Detamore MS. A Comparison of human bone marrow-derived mesenchymal stem cells and human umbilical cord-derived mesenchymal stromal cells for cartilage tissue engineering. Tissue Eng Pt A 2009; 15: 2259-2266.

18. Shabbir A, Cox A, Rodriguez-Menocal L, Salgado M, Badiavas EV. Mesenchymal stem cell exosomes induce proliferation and migration of normal and chronic wound fibroblasts, and enhance angiogenesis in vitro. Stem Cells Dev 2015; 24: 16351647.

19. Salehinejad P, Alitheen NB, Ali AM, Omar AR, Mohit M, Janzamin E, Samani FS, Torshizi Z, Nematollahi-Mahani $\mathrm{SN}$. Comparison of different methods for the isolation of mesenchymal stem cells from human umbilical cord Wharton's jelly. In Vitro Cell Dev Biol Anim 2012; 48: 75-83.

20. Yoon JH, Roh EY, Shin S, Jung NH, Song EY, Chang JU, Kim BJ, Jeon HW. Comparison of explant-derived and enzymatic digestion-derived MSCs and the growth factors from Wharton's jelly. Biomed Res Int 2013; 1: eID428726. 


\section{CEYLAN et al. / Turk J Vet Anim Sci}

21. Chang Z, Hou T, Xing J, Wu X, Jin H, Li Z, Deng M, Xie A, Xu J. Umbilical cord Wharton's jelly repeated culture system: a new device and method for obtaining abundant mesenchymal stem cells for bone tissue engineering. PLoS One 2014; 9: e110764.

22. Ishige I, Nagamura-Inoue T, Honda MJ, Harnprasopwat R, Kido M, Sugimoto M, Nakauchi H, Tojo H. Comparison of mesenchymal stem cells derived from arterial, venous, and Wharton's jelly explants of human umbilical cord. Int J Hematol 2009; 90: 261-9.

23. Weiss ML, Medicetty S, Bledsoe AR, Rachakatla RS, Choi M, Merchav S, Luo Y, Rao MS, Velagaleti G, Troyer D. Human umbilical cord matrix stem cells: preliminary characterization and effect of transplantation in a rodent model of Parkinson's disease. Stem Cells 2006; 24: 781-92.
24. Graham L, Orenstein JM. Processing tissue and cells for transmission electron microscopy in diagnostic pathology and research. Nat Protoc 2007; 2: 2439-50.

25. Pasquinelli G, Tazzari P, Ricci F, Vaselli C, Buzzi M, Conte R, Orrico C, Foroni L, Stella A, Alviano F et al. Ultrastructural characteristics of human mesenchymal stromal (stem) cells derived from bone marrow and term placenta. Ultrastruct Pathol 2007; 31: 23-31.

26. Qiao SM, Chen GH, Wang Y, Wu DP. Ultrastructure of human umbilical cord mesenchymal stem cells. Zhongguo Shi Yan Xue Ye Xue Za Zhi 2012; 20: 443-447 (in Chinese with abstract in English). 